\title{
A Case Report of Intravitreal Bevacizumab for Iris Metastasis of Small Cell Lung Carcinoma with Neovascular Glaucoma
}

\author{
Takako Hidaka Hideki Chuman Nobuhisa Nao-i \\ Department of Ophthalmology, Faculty of Medicine, University of Miyazaki, \\ Miyazaki, Japan
}

\section{Keywords}

Intravitreal bevacizumab · Iris metastasis $\cdot$ Neovascular glaucoma

\begin{abstract}
A 79-year-old man who had been diagnosed with small cell lung carcinoma (SCLC) complained of right ocular pain and blurred vision. His right intraocular pressure (IOP) was $30 \mathrm{~mm} \mathrm{Hg}$, and anterior chamber cells and multiple grayish white iris masses associated with peripheral anterior synechia (PAS) and neovascularization of the right iris were observed. We presumed that the iris masses were iris metastasis of SCLC. Despite therapy with topical eye drops and oral acetazolamide, the IOP was poorly controlled, so we injected intravitreal bevacizumab into his right eye for neovascular glaucoma. Neovascular glaucoma disappeared rapidly, but the IOP did not improve because of total PAS. To our knowledge, there is only one report of the use of intravitreal bevacizumab for SCLC metastasis in that eye and they reported that intravitreal injection resulted in successful short-term regression of presumed iris metastasis and improved control of secondary neovascular glaucoma, and the case had over one-half PAS. The previous report and our results suggest that secondary neovascular glaucoma with iris metastasis may be controlled by early intravitreal bevacizumab injection.
\end{abstract}




\section{Introduction}

Metastasis to the anterior uvea is very rare compared with choroidal metastasis [1-3], with the majority of cases originating from carcinomas in either the breast or lungs [4]. The most common cancer type is non-small cell lung cancer (non-SCLC), and small cell lung carcinoma (SCLC) is rare [3-5]. We report a case of iris metastasis that caused neovascular glaucoma in a patient with SCLC, which was treated with bevacizumab.

\section{Case Report}

A 79-year-old man was referred to our hospital for right iris metastasis on May 17, 2016. He noticed right ocular pain and blurred vision 5 days prior to presentation, and visited his local doctor. He had been diagnosed 11 months earlier with SCLC (cT4N2 or 3M1b with left cerebellar metastasis, and invasion of the trachea and mediastinum.) and had undergone chemotherapy with 2 cycles of carboplatin/etoposide and secondary chemotherapy with amrubicin. His status was regarded as stable disease at that time.

His visual acuity was $0.1\left(0.8 \times \mathrm{S}+1.50 \mathrm{D} \mathrm{Cyl}-0.50 \mathrm{D} \mathrm{A} \times 7^{\circ}\right) \mathrm{OD}$ and $0.5(0.9 \times \mathrm{S}+2.50$ D Cyl $-1.50 \mathrm{D} \mathrm{A} \times 105^{\circ}$ ) OS. His intraocular pressure (IOP) was $30 \mathrm{~mm} \mathrm{Hg}(\mathrm{OD})$ and $10 \mathrm{~mm} \mathrm{Hg}$ (OS) measured using a Goldmann applanation tonometer (GAT). Right relative afferent pupillary defect (RAPD) was positive. Slit-lamp biomicroscopy revealed conjunctival injection and multiple temporal gray irregular iris masses associated with peripheral anterior synechia (PAS) and neovascularization of the iris (Fig. 1a). The PAS index was approximately $10 \%$. The bilateral fundi were normal. Iris masses were observed by anterior optical coherence tomography (OCT) and ultrasound biomicroscopy (UBM). Anterior ocular segment fluorescein angiography revealed leakage due to iris neovascularization (Fig. 2).

The iris masses were presumed to be metastatic from SCLC. We diagnosed him as having neovascular glaucoma due to the iris metastasis from SCLC. We started therapy with topical latanoprost, brinzolamide, timolol maleate, and oral acetazolamide at $500 \mathrm{mg} /$ day. After starting the therapy, the patient was admitted to another hospital to receive radiotherapy for brain metastasis. When he visited our hospital again on June 14, his right IOP had not improved (33 $\mathrm{mm} \mathrm{Hg}$ ); therefore, we injected $1.25 \mathrm{mg}$ of bevacizumab into his right vitreous cavity on July 4 to treat neovascular glaucoma. The use of intravitreal bevacizumab received prior approval from the Miyazaki University Hospital Ethics Committee. After bevacizumab injection, the iris masses rapidly decreased and the neovascularization disappeared (Fig. 1b), but his right IOP did not improve because of the $100 \%$ PAS index. We thus performed trabeculectomy for his right eye on August 8. After surgery, his right IOP decreased to $10 \mathrm{~mm} \mathrm{Hg}$ (GAT), but his right optic disc had already atrophied because of long-term high IOP, and as a result his right visual acuity did not recover (light perception positive OD).

\section{Discussion}

The majority of iris metastases originate from carcinomas of either the breast or lungs. Shields et al. [4] reported that the most common primary site was breast cancer (68\%) in women and lung cancer (40\%) in men. Metastasis to the anterior uveal region is very rare compared with choroidal metastasis. Ferry and Font [1] reported that $62 \%$ were choroidal metastases and $11 \%$ were iris metastases. Shields et al. [2] found that $7.8 \%$ were iris 
metastases. Shah et al. [3] also reported that $88 \%$ had choroidal metastases and $10 \%$ iris metastases from lung cancer.

Non-SCLC was found to predominate over SCLC in cases of uveal metastasis from lung cancer in the study by Shah et al. [3] (non-SCLC vs. SCLC: 46.84 vs. 9.16\%) as well as in the study by Kreusel et al. [5] (77 vs. 23\%).

Treatment of uveal metastasis generally consists of external beam radiotherapy, systemic chemotherapy, brachytherapy, photodynamic therapy, surgical resection, and enucleation [3]. There are also reports of intravitreal injection of anti-VEGF antibodies as treatment for neovascular glaucoma caused by metastasis of iris tumors [6,7]. However, to our knowledge, only one case of intravitreal bevacizumab for neovascular glaucoma caused by SCLC metastasis to the iris has been reported by Nakashima et al. [8]. Bevacizumab is a recombinant humanized monoclonal anti-VEGF. VEGF plays a central role in the regulation of angiogenesis [9]. Tumor angiogenesis is an important characteristic of cancer, and tumor angiogenesis is necessary due to increased metastatic cancer $[10,11]$. Nakashima et al. reported that 2 weeks after the bevacizumab injection, the iris tumor had decreased in size, the iris neovascularization had resolved and IOP had also decreased. In Nakashima et al.'s study, the PAS was over one-half of the angle. On the other hand, in our case, IOP did not decrease after bevacizumab injection because of extensive PAS.

In summary, our case suggests the effectiveness of bevacizumab intravitreal injection for metastatic iris tumors. It also suggests that intravitreal injection of bevacizumab as early as possible enables control of the metastatic iris tumors resulting from SCLC and IOP in neovascular glaucoma patients.

\section{Statement of Ethics}

The authors followed the code of ethics of Miyazaki University.

\section{Disclosure Statement}

The authors declare that there are no conflicts of interest regarding the publication of this paper.

\section{References}

1 Ferry AP, Font RL. Carcinoma metastatic to the eye and orbit. I. A clinicopathologic study of 227 cases. Arch Ophthalmol. 1974 Oct;92(4):276-86.

2 Shields JA, Shields CL, Kiratli H, de Potter P. Metastatic tumors to the iris in 40 patients. Am J Ophthalmol. 1995 Apr;119(4):422-30.

3 Shah SU, Mashayekhi A, Shields CL, Walia HS, Hubbard GB 3rd, Zhang J, et al. Uveal metastasis from lung cancer: clinical features, treatment, and outcome in 194 patients. Ophthalmology. 2014 Jan;121(1):352-7.

4 Shields CL, Shields JA, Gross NE, Schwartz GP, Lally SE. Survey of 520 eyes with uveal metastases. Ophthalmology. 1997 Aug;104(8):1265-76.

5 Kreusel KM, Bechrakis NE, Wiegel T, Krause L, Foerster MH. Incidence and clinical characteristics of symptomatic choroidal metastasis from lung cancer. Acta Ophthalmol. 2008 Aug;86(5):515-9.

6 Seidman CJ, et al. Intravitreal Bevacizumab in the management of breast cancer iris metastasis. Retin Cases Brief Rep. 2017;11(1):47-50

7 Makri OE, Psachoulia C, Exarchou A, Georgakopoulos CD. Intravitreal Ranibizumab as Palliative Therapy for Iris Metastasis Complicated With Refractory Secondary Glaucoma. J Glaucoma. 2016 Jan;25(1):e53-5. 


\section{Case Reports in Ophthalmology}

\begin{tabular}{l|l}
\hline Case Rep Ophthalmol 2018;9:401-404 \\
\hline DOI: 10.1159/000492713 & $\begin{array}{l}\text { @ 2018 The Author(s). Published by S. Karger AG, Basel } \\
\text { www.karger.com/cop }\end{array}$ \\
\hline
\end{tabular}

Hidaka et al.: A Case Report of Intravitreal Bevacizumab for Iris Metastasis of Small Cell Lung Carcinoma with Neovascular Glaucoma

8 Nakashima C, Keino H, Watanabe T, Taki W, Okada AA. Intravitreal bevacizumab for iris metastasis of smallcell lung carcinoma with neovascular glaucoma. Jpn J Ophthalmol. 2011 Jan;55(1):80-1.

9 Ferrara N: Vascular endothelial growth factor. Arterioscler Thromb Vasc Biol. 2009 Jun;29(6):789-91.

10 Ferrara N, Kerbel RS. Angiogenesis as a therapeutic target. Nature. 2005 Dec;438(7070):967-74.

11 Sato Y: Antibodies targeting VEGF signaling. Nippon Rinsho. 2014;72(Suppl 2).
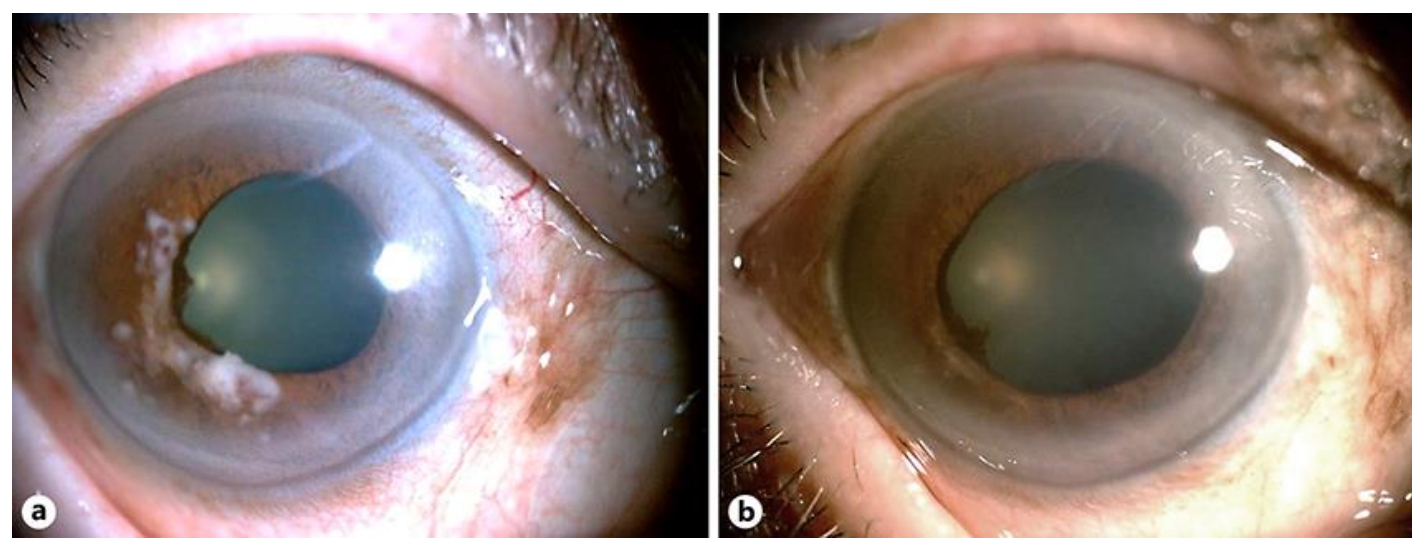

Fig. 1. a Slit-lamp examination before intravitreal bevacizumab. There were multiple temporal gray irregular iris masses associated with PAS and neovascularization of the iris. b Slit-lamp examination 1 month after intravitreal bevacizumab. The iris neovascularization disappeared and iris atrophy was noted where the original tumor had been.

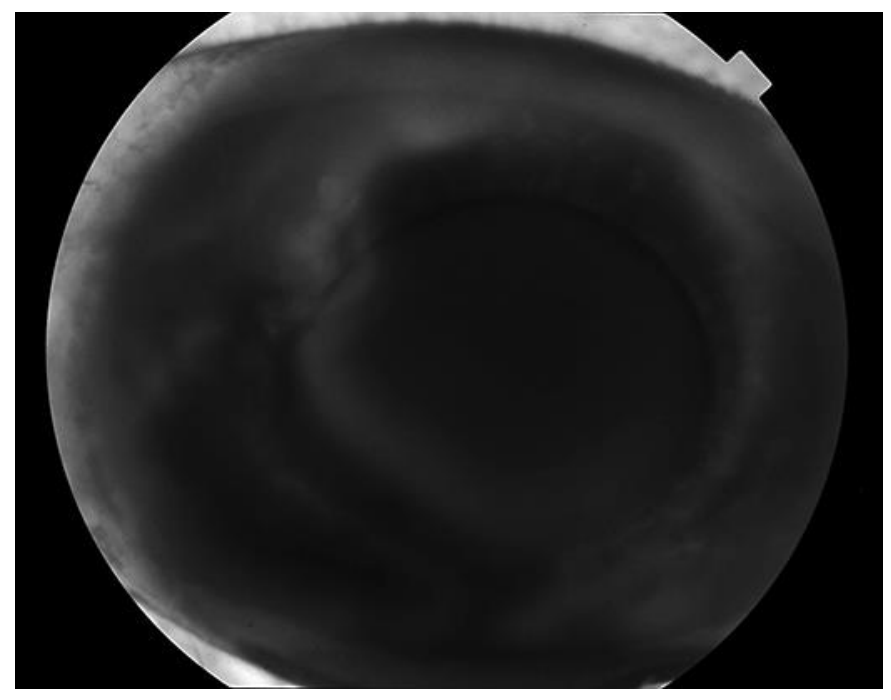

Fig. 2. Anterior ocular segment fluorescein angiography $4 \min 24 \mathrm{~s}$ after injection showed leakage due to iris neovascularization. 